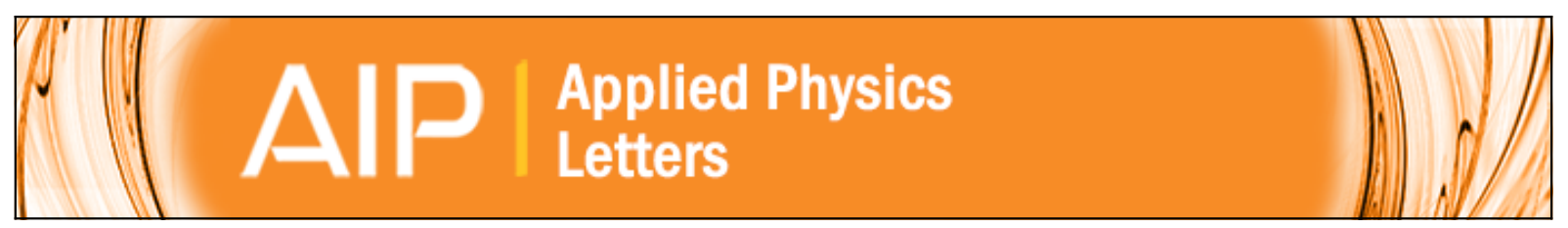

\title{
Carrier injection dynamics in heterojunction solar cells with bipolar molecule
}

Yosuke Takahashi, Takeshi Yasuda, Kouhei Yonezawa, and Yutaka Moritomo

Citation: Applied Physics Letters 106, 123902 (2015); doi: 10.1063/1.4914918

View online: http://dx.doi.org/10.1063/1.4914918

View Table of Contents: http://scitation.aip.org/content/aip/journal/apl/106/12?ver=pdfcov

Published by the AIP Publishing

\section{Articles you may be interested in}

Spatially resolved spectral mapping of phase mixing and charge transfer excitons in bulk heterojunction solar cell films

Appl. Phys. Lett. 100, 073308 (2012); 10.1063/1.3687185

Increased open-circuit voltage in bulk-heterojunction solar cells using a C 60 derivative

Appl. Phys. Lett. 97, 193309 (2010); 10.1063/1.3518066

Electrical characterization of single-walled carbon nanotubes in organic solar cells by Kelvin probe force microscopy

Appl. Phys. Lett. 96, 083302 (2010); 10.1063/1.3332489

Imbalanced charge mobility in oxygen treated polythiophene/fullerene based bulk heterojunction solar cells Appl. Phys. Lett. 95, 263305 (2009); 10.1063/1.3279135

Cathode dependence of the open-circuit voltage of polymer:fullerene bulk heterojunction solar cells J. Appl. Phys. 94, 6849 (2003); 10.1063/1.1620683

Want to publish your paper in the \#1 MOST CITED journal in applied physics?

With Applied Physics Letters, you can.

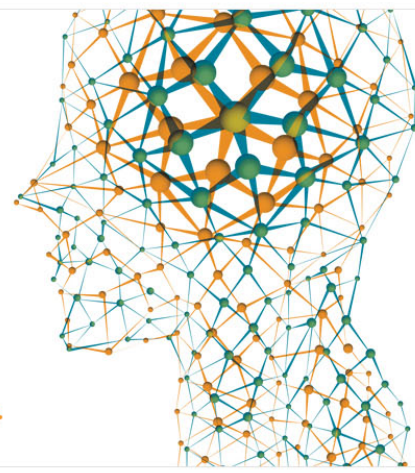




\title{
Carrier injection dynamics in heterojunction solar cells with bipolar molecule
}

\author{
Yosuke Takahashi, ${ }^{1}$ Takeshi Yasuda, ${ }^{2, a)}$ Kouhei Yonezawa, ${ }^{1}$ and Yutaka Moritomo ${ }^{1,3, a)}$ \\ ${ }^{1}$ Graduate School of Pure and Applied Science, University of Tsukuba, Tsukuba 305-8571, Japan \\ ${ }^{2}$ Photovoltaic Materials Unit, National Institute for Materials Science (NIMS), Tsukuba 305-0047, Japan \\ ${ }^{3}$ Center for Integrated Research in Fundamental Science and Engineering (CiRfSE), University of Tsukuba, \\ Tsukuba 305-8571, Japan
}

(Received 29 January 2015; accepted 3 March 2015; published online 23 March 2015)

\begin{abstract}
A boron subphthalocyanine chloride (SubPc) is a bipolar molecule and is used in hetero-junction organic solar cells. Here, we investigated the carrier injection dynamics from the donor $\alpha$-sexithiophene (6T) or acceptor $\mathrm{C}_{60}$ layers to the bipolar SubPc layer by means of the femtosecond timeresolved spectroscopy. We observed gradual increase of the $\mathrm{SubPc}^{-}\left(\mathrm{SubPc}^{+}\right)$species within $\approx 300$ ps. The increases are interpreted in terms of the exciton diffusion within the $6 \mathrm{~T}\left(\mathrm{C}_{60}\right)$ layer and subsequent electron (hole) injection at the interface. In $6 \mathrm{~T} / \mathrm{SubPc}$ heterojunction, the electron injection is observed even at $80 \mathrm{~K}$. The robust electron injection is ascribed to the efficient charge separation within the 6T layer under photo exciation at $400 \mathrm{~nm}$. (C) 2015 AIP Publishing LLC.
\end{abstract}

[http://dx.doi.org/10.1063/1.4914918]

Organic solar cells (OSCs) are potential alternatives to the conventional inorganic solar cells due to their low-cost processing and compatibility with flexible substrates. The active layers of OSCs usually consist of donor (D) and acceptor (A) materials. The photocarriers, i.e., the donor holes and the acceptor electrons, are created at the D/A interface by exciton dissociation. The development of low-band gap donor polymers, e.g., poly-[[4,8-bis[(2-ethylhexyl)oxy]benzo $\left[1,2-b: 4,5-b^{\prime}\right]$ dithiophene-2,6-diyl][3-fluoro-2-[(2-ethylhexyl)carbonyl]thieno[3,4-b] thiophenediyl] (PTB7), ${ }^{1,2}$ increases the power conversion efficiency (PCE) of OSCs in the last decade. On the other hand, the fullerene molecules and their derivatives, i.e., [6,6]-phenyl $\mathrm{C}_{61}$-butyric acid methyl ester (PCBM) and [6,6]-phenyl $\mathrm{C}_{71}$-butyric acid methyl ester $\left(\mathrm{PC}_{71} \mathrm{BM}\right)$, have been the dominant acceptor materials in OSCs due to their good electron-accepting ability and high electron mobility. Recently, bipolar molecules, e.g., boron subphthalocyanine chloride (SubPc) and its homologue boron subnaphthalocyanine chloride (SubNc), are found to be alternatives to the fullerene in heterojunction OSCs. ${ }^{3-8}$ Reflecting the bipolar nature, ${ }^{8}$ SubPc can be used even as a donor material in heterojunction OSCs with $\mathrm{C}_{60}$ as an acceptor. ${ }^{9,10}$ Especially, the bipolar nature of SubPc and SubNc enables cascade heterojunction OCSs, ${ }^{3,5-7}$ whose PCEs reach to $8.4 \% .^{3}$ However, the carrier injection dynamics in the heterojunction OSCs with bipolar molecule remains unclear.

The femtosecond time-resolved spectroscopy is a powerful tool to reveal the charge formation dynamics in OSCs in femtosecond to picosecond time domain. ${ }^{11-22}$ Careful analyses of the photoinduced absorptions (PIAs) clarify the relative numbers of excitons and carriers. For example, Hwang et al. ${ }^{11}$ investigated the charge dynamics in poly-(3-hexylthiophene) (P3HT)/PCBM blend film and proposed a two-step process for charge generation, i.e., formation of the interfacial $\mathrm{CT}$ states $(\leq 250 \mathrm{fs})$ followed by the carrier formation $(=4 \mathrm{ps})$. In PTB7/PC ${ }_{71} \mathrm{BM}$ blend film, ${ }^{19}$

\footnotetext{
${ }^{\text {a) }}$ Authors to whom correspondence should be addressed. Electronic addresses: YASUDA.Takeshi@nims.go.jp and moritomo.yutaka.gf@u.tsukuba.ac.jp
}

the spectroscopy revealed the decrease in the exciton number and the increase in carrier number within $0.3 \mathrm{ps}$. This indicates a fast conversion process from exciton to carrier. A similar exciton-carrier conversion process is reported in small molecular bulk heterojunction OSC, 2,5-di-(2-ethyl-

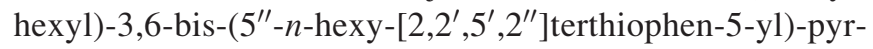
rolo[3,4-c]pyrrolo-1,4-dione (SMDPPEH)/PC ${ }_{71} \mathrm{BM}$, within $\sim 1$ ps. $^{20}$

In this letter, we investigated the carrier injection dynamics from the donor $\alpha$-sexithiophene (6T) or acceptor $\mathrm{C}_{60}$ layers to the SubPc layer by means of the femtosecond timeresolved spectroscopy. We spectroscopically observed gradual increase of the $\mathrm{SubPc}^{-}\left(\mathrm{SubPc}^{+}\right)$species within $\approx 300 \mathrm{ps}$. We ascribed the slow carrier injection to the migration of the $6 \mathrm{~T}$ $\left(\mathrm{C}_{60}\right)$ exciton within the 6T $\left(\mathrm{C}_{60}\right)$ layer.

First, we fabricated $6 \mathrm{~T} / \mathrm{SubPc}\left(\mathrm{SubPc} / \mathrm{C}_{60}\right)$ heterojunction cells in the following configuration: indium tin oxide (ITO)/poly-(3,4-ethylenedioxythiophene) (PEDOT): poly(styrenesulfonate) (PSS) (40 nm)/active layer/1,3,5-Tri(1phenyl-1H-benzo[d]imidazol-2-yl)phenyl (TPBi) (8 nm)/ $\mathrm{Mg}: \mathrm{Ag}$. The patterned ITO (conductivity: $10 \Omega / \mathrm{sq}$ ) glass was pre-cleaned in an ultrasonic bath of acetone and ethanol and then treated in an ultraviolet-ozone chamber. A thin layer of PEDOT:PSS was spin-coated onto the ITO and dried at $110^{\circ} \mathrm{C}$ for $10 \mathrm{~min}$ on a hot plate in air. Then, the active layers, $6 \mathrm{~T}(25 \mathrm{~nm}) / \mathrm{SubPc}(25 \mathrm{~nm})$ or SubPc $(25 \mathrm{~nm}) / \mathrm{C}_{60}$ $(25 \mathrm{~nm})$ bilayer, were deposited by vacuum evaporation. Finally, TPBi and $\mathrm{Mg}: \mathrm{Ag}$ were deposited onto the active layer by conventional thermal evaporation at a chamber pressure lower than $5 \times 10^{-4} \mathrm{~Pa}$, which provided the devices with an active area of $5 \times 2 \mathrm{~mm}^{2}$.

Figure 1 shows the $J-V$ curves of (a) $6 \mathrm{~T} / \mathrm{SubPc}$ and (b) $\mathrm{SubPc} / \mathrm{C}_{60}$ heterojunction devices. The current densityvoltage $(J-V)$ curves were measured using an ADCMT 6244 DC voltage current source/monitor under AM 1.5 solarsimulated light irradiation of $100 \mathrm{~mW} \mathrm{~cm}{ }^{-2}$ (OTENTOSUN III, Bunkou-keiki Co., Ltd.). The incident-photon-tocurrent conversion efficiency (IPCE) spectrum was measured using a SM-250 system (Bunkou-keiki Co., Ltd.). The 


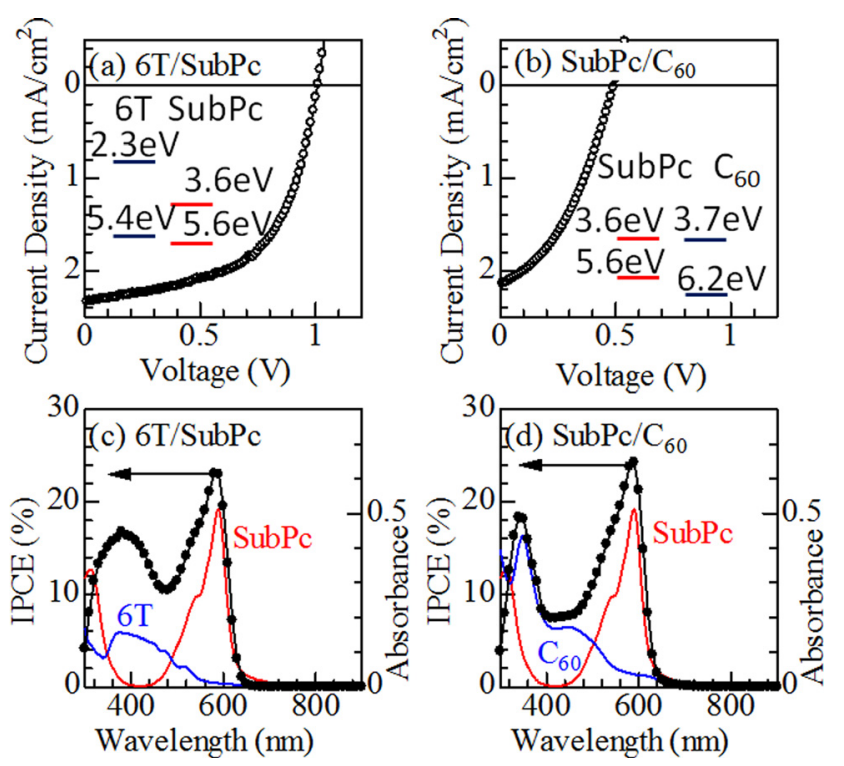

FIG. 1 . $J-V$ curves of (a) $6 \mathrm{~T} / \mathrm{SubPc}$ and (b) $\mathrm{SubPc} / \mathrm{C}_{60}$ heterojunction devices. Insets show energy diagrams. (c) IPCE spectrum of the $6 \mathrm{~T} / \mathrm{SubPc}$ cell together with absorption spectra of the 6T and SubPc neat films. (d) IPCE spectrum of the SubPc/C $\mathrm{C}_{60}$ cell together with absorption spectra of the SubPc and $\mathrm{C}_{60}$ neat films.

6T/SubPc device exhibits an open circuit voltage $\left(V_{\mathrm{oc}}\right)$ of $1.00 \mathrm{~V}$, a short circuit current $\left(J_{\mathrm{sc}}\right)$ of $2.33 \mathrm{~mA} \mathrm{~cm}^{-2}$, a fill factor (F.F.) of 0.58 , and a PCE of $1.35 \%$. The $\mathrm{SubPc} / \mathrm{C}_{60} \mathrm{de}-$ vice exhibits a $V_{\mathrm{oc}}$ of $0.49 \mathrm{~V}$, a $J_{\mathrm{sc}}$ of $2.15 \mathrm{~mA} \mathrm{~cm}^{-2}$, a F.F. of 0.39 , and a PCE of $0.41 \%$. Thus, we confirmed that SubPc acts as a bipolaor material in heterojunction devices.

For the time-resolved experiment, we fabricated $6 \mathrm{~T}, \mathrm{C}_{60}$, and SubPc neat films and $6 \mathrm{~T} / \mathrm{SubPc}$ and $\mathrm{SubPc} / \mathrm{C}_{60}$ bilayer films. The three neat films were fabricated by vacuum evaporation on quartz substrates. The thicknesses of the three films were $25 \mathrm{~nm}$. The $6 \mathrm{~T} / \mathrm{SubPc}$ bilayer film was fabricated by vacuum evaporation of SubPc $(25 \mathrm{~nm})$ on $6 \mathrm{~T}$ film $(25 \mathrm{~nm})$, while the $\mathrm{SubPc} / \mathrm{C}_{60}$ bilayer film was fabricated by vacuum evaporation of $\mathrm{C}_{60}(25 \mathrm{~nm})$ on SubPc film $(25 \mathrm{~nm})$. The atomic force microscope (AFM) image of the 6T film consists of $\sim 500 \times 300 \mathrm{~nm}^{2}$ grains of $6 \mathrm{~T}$ microcrystals while that of SubPc film consists of much smaller grains $(<100 \mathrm{~nm})$.

The time-resolved spectroscopy was carried out in a pump-probe configuration. Details were described in literature. ${ }^{19}$ The pump pulse at $400 \mathrm{~nm}$ was generated as the second harmonics of a regenerative amplified Ti:sapphire laser in a $\beta-\mathrm{BaB}_{2} \mathrm{O}_{4}(\mathrm{BBO})$ crystal. The pulse width and repetition rate were $100 \mathrm{fs}$ and $1000 \mathrm{~Hz}$, respectively. The pump pulse selectively excites the $6 \mathrm{~T}$ and $\mathrm{C}_{60}$ layers, since the SubPc has a window at $400 \mathrm{~nm}$ [Fig. 1(c)]. A white probe pulse $(450-1600 \mathrm{~nm})$ was generated by self-phase modulation in a sapphire plate and was focused on the sample with the pump pulse. The spot sizes of the pump and probe pulses were 4.5-5.0 and 2.0-2.5 $\mathrm{mm}$ in diameter, respectively. The spectra of the transmitted probe pulse were detected using a 72ch Si photodiode array (450-900 nm) attached at the exit of a $30 \mathrm{~cm}$ imaging spectrometer. The differential absorption spectrum $(\Delta \mathrm{OD})$ is expressed as $-\log \left(\frac{I_{\text {on }}}{I_{\text {off }}}\right)$, where $I_{\text {on }}$ and $I_{\text {off }}$ are the transmission spectra under the pump-on and pump-off conditions, respectively.
The second and third panels of Fig. 2 show $\triangle \mathrm{mOD}$ spectra of the 6T, SubPc, and $\mathrm{C}_{60}$ neat films at $300 \mathrm{~K}$. The $6 \mathrm{~T}$ neat film shows PIA due to exciton above $700 \mathrm{~nm}$ [second panel of (a)]. The SubPc neat film shows the negative signal at $600 \mathrm{~nm}$, which is ascribed to the ground state bleaching (GSB) [third panel of (a)]. The $\mathrm{C}_{60}$ neat film shows PIA due to exciton above $500 \mathrm{~nm}$ [second panel of (b)]. ${ }^{23}$ The bottom panels of Fig. 2 show $\Delta \mathrm{mOD}$ spectra of the $6 \mathrm{~T} / \mathrm{SubPc}$ and SubPc/C 60 bilayer films at $300 \mathrm{~K}$. In (a) $6 \mathrm{~T} / \mathrm{SubPc}$ bilayer film, the overall feature of the 1 ps spectrum, i.e., positive signal at $500 \mathrm{~nm}$ and above $700 \mathrm{~nm}$ with a dip structure at $600 \mathrm{~nm}$, is well understood by superposition of the 1 ps spectra of the $6 \mathrm{~T}$ and SubPc neat films. We emphasize that the 1000 ps spectrum shows an additional PIA at $622 \mathrm{~nm}$ (open triangle). Similarly, the overall feature of the 1 ps spectrum of (b) SubPc/ $\mathrm{C}_{60}$ bilayer film is well understood by superposition of the 1 ps spectra of the SubPc and $\mathrm{C}_{60}$ neat films. We observed an additional PIA at $615 \mathrm{~nm}$ (open triangle) in the 1000 ps spectrum.

In Fig. 3, we replotted the 1000 ps spectra against photon energy. We found that the overall feature of (a) 6T/ SubPc bilayer film, i.e., positive peak at $1.95 \mathrm{eV}$ and $2.45 \mathrm{eV}$ with a dip structure at $2.05 \mathrm{eV}$, is similar to that of $\mathrm{SubNc}^{-},{ }^{24}$ except for the energy shift of $+0.2 \mathrm{eV}$ [Figs. 3(a) and 3(c)]. Therefore, we ascribed the additional PIA to the $\mathrm{SubPc}^{-}$species, which are created by the electron injection at the $6 \mathrm{~T} / \mathrm{SubPc}$ interface. Similarly, the overall feature of (b) $\mathrm{SubPc} / \mathrm{C}_{60}$ bilayer film is similar to that of $\mathrm{SubNc}^{+}{ }^{24}$ except for the energy shift of $+0.25 \mathrm{eV}$ [Figs. 3(b) and 3(d)]. We ascribed the additional PIA to the $\mathrm{SubPc}^{+}$species, which are created by the hole injection at the $\mathrm{SubPc} / \mathrm{C}_{60}$ interface. Looking at the third panel of Fig. 2, we observed a longlived signal in the 1000 ps spectrum of the neat SubPc film. The spectral shape is similar to those of $\mathrm{SubPc}^{-}$[Fig. 3(c)]
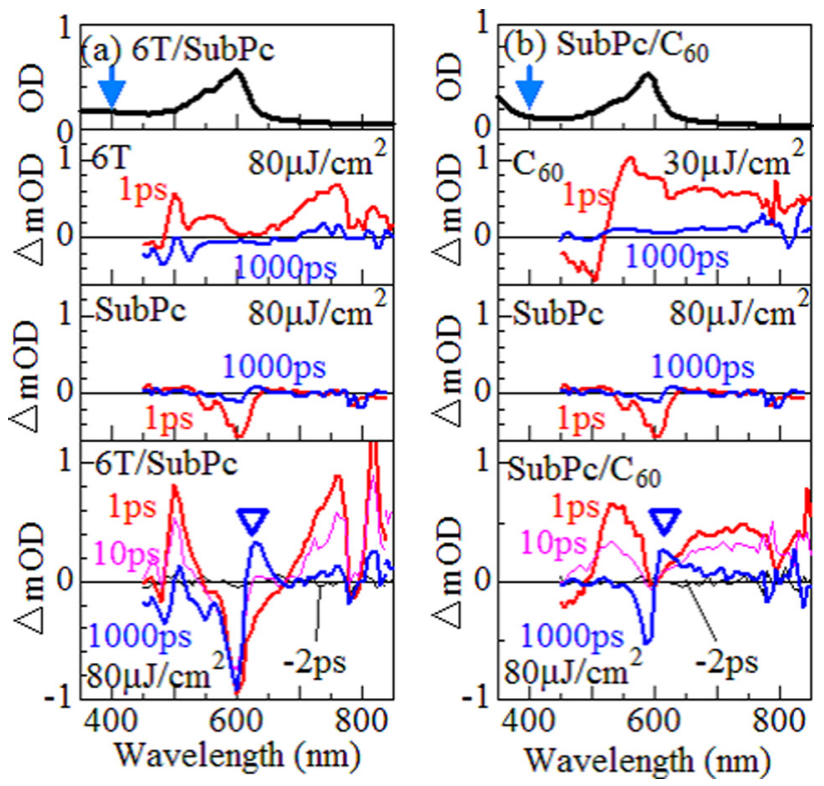

FIG. 2. (a) $\Delta \mathrm{mOD}$ spectra of $6 \mathrm{~T}$ neat, SubPc neat, and $6 \mathrm{~T} / \mathrm{SubPc}$ bilayer films. Top panel shows absorption spectrum of the $6 \mathrm{~T} / \mathrm{SubPc}$ bilayer film. (b) $\Delta \mathrm{mOD}$ spectra of $\mathrm{C}_{60}$ neat, SubPc neat, and $\mathrm{SubPc} / \mathrm{C}_{60}$ bilayer films. Top panel shows absorption spectrum of the $\mathrm{SubPc} / \mathrm{C}_{60}$ bilayer film. The downward arrows indicate the excitation wavelength. The open triangles indicate additional PIAs. The dip structures at $800 \mathrm{~nm}$ are due to the notch filter. 

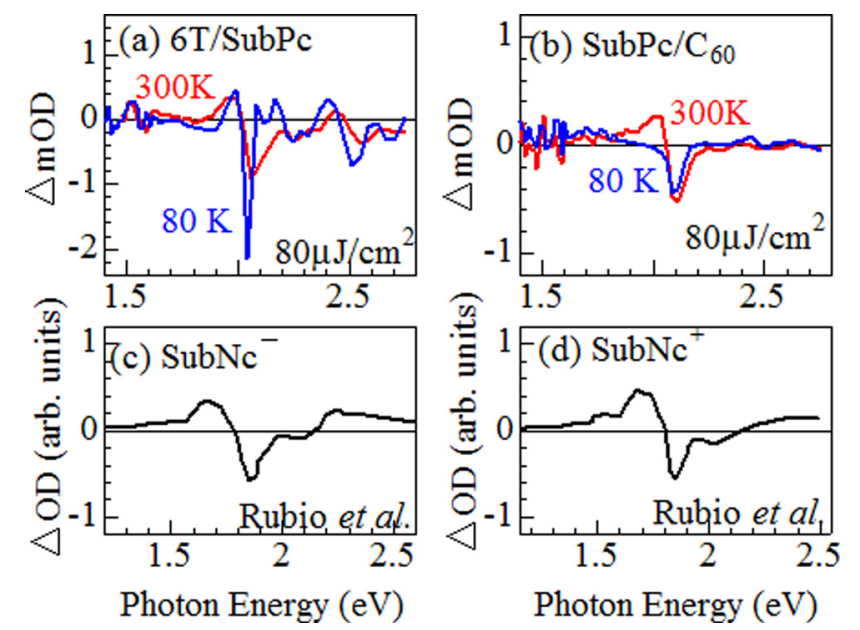

FIG. 3. $\Delta \mathrm{mOD}$ spectra $\left(t=1000 \mathrm{ps}\right.$ ) of (a) $6 \mathrm{~T} / \mathrm{SubPc}$ and (b) $\mathrm{SubPc} / \mathrm{C}_{60}$ bilayer films at $300 \mathrm{~K}$ and $80 \mathrm{~K}$. $\Delta \mathrm{OD}$ spectra of (c) $\mathrm{SubNc}^{-}$and (d) $\mathrm{SubNc}^{+}$(cited from Ref. 24).

and $\mathrm{SubPc}^{+}$[Fig. 3(d)]. Then, the long-lived component should be ascribed to the $\mathrm{SubPc}^{-}$and $\mathrm{SubPc}^{+}$species. They are probably photocreated in the SubPc layer, reflecting the bipolar nature of SubPc.

The bottom panel of Fig. 4(a) shows time $(t)$-dependence of the PIA signal due to $\mathrm{SubPc}^{-}$in the $6 \mathrm{~T} / \mathrm{SubPc}$ bilayer film. The PIA intensity gradually increases with $t$. The increase is roughly reproduced by an exponential function with rise time $(\tau)$ of $312 \mathrm{ps}$, neglecting the weak signals from the $6 \mathrm{~T}$ and SubPc layers (upper panel). The bottom panel of Fig. 4(b) shows $t$-dependence of the GSB signal of SubPc. The $t$-dependence is well reproduced by sum of the exponential function $(\tau=312 \mathrm{ps})$ and the signal $\left(f_{\mathrm{SubPc}}(t)\right.$ $\left.\propto-\mathrm{e}^{t / 7}-0.67 \mathrm{e}^{-t / 1100}\right)$ from the SubPc layer. Similar $t$-dependences of the PIA and GSB signals are observed in the $\mathrm{SubPc} / \mathrm{C}_{60}$ bilayer film. The bottom panels of Fig. 5 show $t$-dependences of (a) PIA signal due to $\mathrm{SubPc}^{+}$and (b) GSB of SubPc in the SubPc/C 60 bilayer film. As indicated by solid curves, the $t$-dependences are reproduced by an exponential function $(\tau=329 \mathrm{ps})$. We note that the signals from

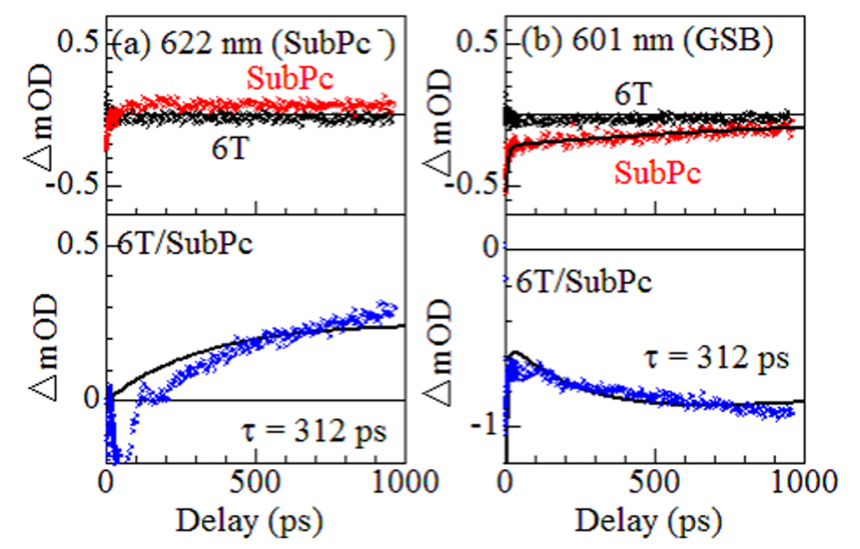

FIG. 4. Temporal evolutions of $\Delta \mathrm{mOD}$ at (a) $622 \mathrm{~nm}$ and (b) $601 \mathrm{~nm}$ in $6 \mathrm{~T}$ and SubPc neat films (upper) and 6T/SubPc bilayer film (bottom). The solid curve in the upper penal of (b) is the result of the least-squares fitting with two exponential functions: $f_{\text {SubPc }}(t) \propto-\mathrm{e}^{t / 7}-0.67 \mathrm{e}^{-t / 1100}$. The solid curve in the bottom panel of (a) is the result of the least-square fitting with an exponential function. The solid curve in the bottom panel of (b) is the result of the least-square fitting with sum of the exponential function and $f_{\mathrm{SubPc}}(t)$.
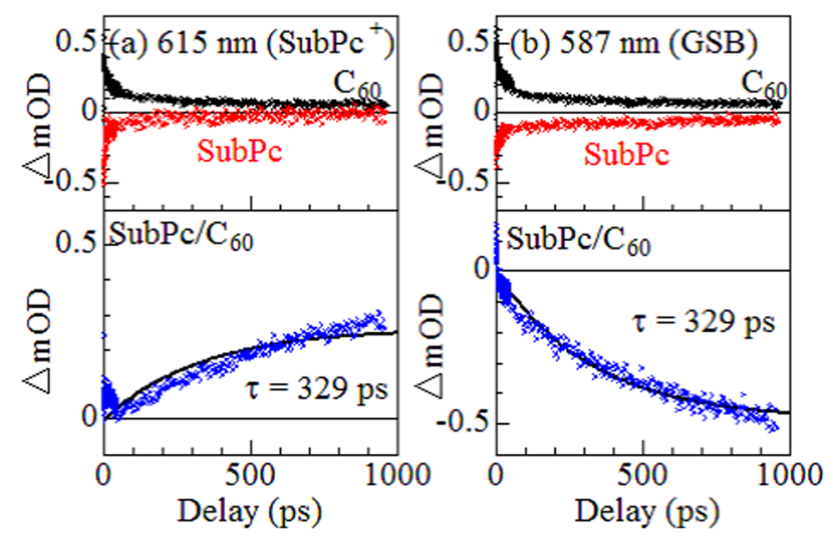

FIG. 5. Temporal evolutions of $\Delta \mathrm{mOD}$ at (a) $615 \mathrm{~nm}$ and (b) $587 \mathrm{~nm}$ in $\mathrm{C}_{60}$ and SubPc neat films (upper) and $\mathrm{C}_{60} / \mathrm{SubPc}$ bilayer film (bottom). The solid curves in the bottom panels are results of the least-square fittings with an exponential function.

the $\mathrm{C}_{60}$ and SubPc layers nearly cancel for $\geq 100$ ps (upper panels). The formation times $(\tau \approx 300 \mathrm{ps})$ in our heterojunction devices are much longer than those in bulk heterojunction devices, e.g., $0.3 \mathrm{ps}$ in $\mathrm{PTB}_{7} / \mathrm{PC}_{71} \mathrm{BM}^{19}$ and $1.3 \mathrm{ps}$ in SMDPPEH/PC ${ }_{71} \mathrm{BM}^{20} \mathrm{We}$ ascribed the slow carrier injection to the migration of the $6 \mathrm{~T}\left(\mathrm{C}_{60}\right)$ exciton within the $6 \mathrm{~T}$ $\left(\mathrm{C}_{60}\right)$ layer.

We further investigated effects of the carrier injection on the relaxation dynamics of the $6 \mathrm{~T}$ and $\mathrm{C}_{60}$ excitons. The dynamics of the $6 \mathrm{~T}$ and $\mathrm{C}_{60}$ excitons were monitored at $759 \mathrm{~nm}$ and $529 \mathrm{~nm}$, respectively. The relaxation curves were analyzed with two exponential functions. The obtained parameters are listed in Table I. The faster and slower components are ascribed to the singlet and triplet excitons, respectively. In the case of the 6T exciton, the lifetime $\left(\tau_{\text {fast }}\right)$ of the singlet exciton is shorter in the $6 \mathrm{~T} / \mathrm{SubPc}$ bilayer film. In the case of the $\mathrm{C}_{60}$ exciton, the lifetimes of the singlet $\left(\tau_{\text {fast }}\right)$ and triplet $\left(\tau_{\text {slow }}\right)$ excitons are shorter in the SubPc/C 60 bilayer film. The shorter lifetimes are ascribed to the additional relaxation channel, i.e., exciton dissociation due to carrier injection to the SubPc layer.

Finally, let us discuss temperature effects on the carrier injection. In Fig. 3, we plotted $\triangle \mathrm{mOD}$ spectra at $80 \mathrm{~K}$ in (a) $6 \mathrm{~T} / \mathrm{SubPc}$ and (b) $\mathrm{SubPc} / \mathrm{C}_{60}$ heterojunctions. In (a) $6 \mathrm{~T} /$ SubPc heterojunction, we clearly observed the PIA signal due to $\mathrm{SubPc}^{-}$. Similar robust carrier formations are observed in the bulk heterojunction OSCs, e.g., P3HT/ $\mathrm{PCBM}^{21}$ and $\mathrm{PTB} 7 / \mathrm{PC}_{71} \mathrm{BM}^{22}$ The robust carrier injection is perhaps ascribed to the efficient charge separation within the $6 \mathrm{~T}$ layer under photo excitation at $400 \mathrm{~nm} .^{25-27}$ Actually, we observed oscillatory structures in the neat $6 \mathrm{~T}$ film around

TABLE I. Relaxation times and amplitudes of the $6 \mathrm{~T}$ and $\mathrm{C}_{60}$ excitons. The parameters were obtained by least-squares fittings with exponential functions, $\Delta \mathrm{mOD}=C_{\text {fast }} \cdot \mathrm{e}^{-\frac{t}{\tau_{\text {fast }}}}+C_{\text {slow }} \cdot \mathrm{e}^{-\frac{t}{\tau_{\text {slow }}}}$.

\begin{tabular}{lccccc}
\hline \hline Exciton & Film & $C_{\text {fast }}$ & $\tau_{\text {fast }}(\mathrm{ps})$ & $C_{\text {slow }}$ & $\tau_{\text {slow }}(\mathrm{ps})$ \\
\hline $6 \mathrm{~T}$ & $6 \mathrm{~T}$ & 0.26 & 19 & 0.29 & 1100 \\
$6 \mathrm{~T}$ & $6 \mathrm{~T} / \mathrm{SubPc}$ & 0.45 & 14 & 0.34 & 1000 \\
$\mathrm{C}_{60}$ & $\mathrm{C}_{60}$ & 0.28 & 21 & 0.16 & 1360 \\
$\mathrm{C}_{60}$ & $\mathrm{SubPc} / \mathrm{C}_{60}$ & 0.38 & 8 & 0.26 & 250 \\
\hline \hline
\end{tabular}


$500 \mathrm{~nm}$ [Fig. 2(a)], which are ascribed to the $6 \mathrm{~T}^{+}-6 \mathrm{~T}^{-}$ pairs. ${ }^{25-27}$ The structures are discernible even at $1000 \mathrm{ps,}$ suggesting that the individual $6 \mathrm{~T}^{+}$and $6 \mathrm{~T}^{-}$are stable in the $6 \mathrm{~T}$ layer. Then, some part of the $6 \mathrm{~T}^{-}$species can reach the $\mathrm{D} / \mathrm{A}$ interface and inject electrons to the SubPc layer. We emphasize that the electron injection from $6 \mathrm{~T}^{-}$is free from Coulombic attraction. In (b) $\mathrm{SubPc} / \mathrm{C}_{60}$ heterojunction, however, the PIA signal due to $\mathrm{SubPc}^{+}$is absent at $80 \mathrm{~K}$. This is probably because the photoinduced charge separation within the $\mathrm{C}_{60}$ layer is not so efficient.

In conclusion, we spectroscopically observed electron (hole) injection from the donor 6T (acceptor $\mathrm{C}_{60}$ ) layer to the bipolar SubPc layer. The carrier injections are very slow ( $\tau \approx 300 \mathrm{ps}$ ) in the heterojunction devices. We ascribed the slow carrier injection to the migration of the $6 \mathrm{~T}\left(\mathrm{C}_{60}\right)$ exciton within the $6 \mathrm{~T}\left(\mathrm{C}_{60}\right)$ layer.

This work was supported by Futaba Electronics Memorial Foundation and a Grant-in-Aid for Young Scientists (B) (22750176) from Scientific Research from the Ministry of Education, Culture, Sports, Science and Technology, Japan.

${ }^{1}$ Y. Liang, Z. Xu, J. Xia, S.-T. Tsai, Y. Wu, G. Li, C. Ray, and L. Yu, Adv. Energy Mater. 22, E135 (2010).

${ }^{2}$ Z. He, C. Zhong, S. Su, M. Xu, H. Wu, and Y. Cao, Nat. Photonics 6, 593 (2012).

${ }^{3}$ K. Cnops, B. P. Rand, D. Cheyns, B. Verreet, M. A. Empl, and P. Heremans, Nat. Commun. 5, 3406 (2014).

${ }^{4}$ N. Beaumont, S. W. Cho, P. Sullivan, D. Newby, K. E. Smith, and T. S. Jones, Adv. Funct. Mater. 22, 561 (2012).

${ }^{5}$ K. Cnops, B. P. Rand, D. Cheyns, and P. Heremans, Appl. Phys. Lett. 101, 143301 (2012).

${ }^{6}$ A. Barito, M. E. Sykes, D. Bilby, J. Amonoo, Y. Jin, S. E. Morris, P. F. Green, J. Kim, and M. Shtein, J. Appl. Phys. 113, 203110 (2013).
${ }^{7}$ A. Barito, M. E. Sykes, B. Huang, D. Bilby, B. Frieberg, J. Kim, P. F. Green, and M. Shtein, Adv. Energy Mater. 4, 1400216 (2014).

${ }^{8}$ T. Yasuda and T. Tsutsui, Mol. Cryst. Liq. Cryst. 462, 3 (2006).

${ }^{9}$ G. E. Morse and T. P. Bender, Appl. Meter. Interface 4, 5055 (2012).

${ }^{10}$ K. L. Mutolo, E. I. Mayo, B. P. Rand, S. R. Forrest, and M. E. Thompson, J. Am. Chem. Soc. 128, 8108 (2006).

${ }^{11}$ I.-W. Hwang, D. Moses, and A. J. Heeger, J. Phys. Chem. C 112, 4350 (2008).

${ }^{12}$ J. Guo, H. Ohkita, H. Benten, and S. Ito, J. Am. Chem. Soc. 131, 16869 (2009).

${ }^{13}$ J. Guo, H. Ohkita, H. Benten, and S. Ito, J. Am. Chem. Soc. 132, 6154 (2010).

${ }^{14}$ K. Yonezawa, H. Kamioka, T. Yasuda, L. Han, and Y. Moritomo, Adv. Opt. Technol. 2012, 316045 (2012).

${ }^{15}$ R. A. Marsh, J. M. Hodgkiss, S. Albert-Seifried, and R. H. Friend, Nano Lett. 10, 923 (2010).

${ }^{16}$ J. Guo, Y. Liang, J. Szarko, B. Lee, H.-J. Son, B. S. Rolczynski, L. Yu, and L. X. Chen, J. Phys. Chem. B 114, 742 (2010).

${ }^{17}$ J. M. Szarko, J.-C. Guo, B. S. Rolczynski, and L. X. Chen, J. Mater. Chem. 21, 7849 (2011)

${ }^{18}$ B. S. Rolczynski, J. M. Szarko, H. J. Son, Y. Liang, L. Yu, and L. X. Chen, J. Am. Chem. Soc. 134, 4142 (2012).

${ }^{19}$ K. Yonezawa, H. Kamioka, T. Yasuda, L. Han, and Y. Moritomo, Jpn. J. Appl. Phys., Part 1 52, 062405 (2013).

${ }^{20}$ T. Akaba, K. Yonezawa, H. Kamioka, T. Yasuda, L. Han, and Y. Moritomo, Appl. Phys. Lett. 102, 133901 (2013).

${ }^{21}$ Y. Moritomo, K. Yonezawa, and T. Yasuda, Appl. Phys. Lett. 105, 073902 (2014).

${ }^{22}$ K. Yonezawa, H. Kamioka, T. Yasuda, L. Han, and Y. Moritomo, Appl. Phys. Lett. 103, 173901 (2013).

${ }^{23}$ D. Dick, X. Wei, S. Jeglinski, R. E. Benner, Z. V. Vardeny, D. Moses, V. I. Srdanov, and F. Wudl, Phys. Rev. Lett. 73, 2760 (1994).

${ }^{24}$ N. Rubio, A. Jiménez-Banzo, T. Torres, and S. Nonell, J. Photochem. Photobiol. A 185, 214 (2007).

${ }^{25}$ K. Watanabe, T. Asahi, H. Fukumura, H. Masuhara, K. Hamano, and T. Kurata, J. Phys. Chem. B 101, 1510 (1997).

${ }^{26}$ K. L. M. Bilnov, S. P. Palto, G. Rauni, C. Taliani, A. A. Tevosov, S. G. Yudin, and R. Zamboni, Chem. Phys. Lett. 232, 401 (1995).

${ }^{27}$ O. Dippel, V. Brandi, H. Bässler, R. Danieli, R. Zamboni, and C. Taliani, Chem. Phys. Lett. 216, 418 (1993). 